Revista Tecné, Episteme y Didaxis: TED. Año 2014, Número Extraordinario. ISSN Impreso: 0121-3814, ISSN web: 2323-0126

Memorias, Sexto Congreso Internacional sobre Formación de Profesores de Ciencias. 08 al 10 de octubre de 2014, Bogotá

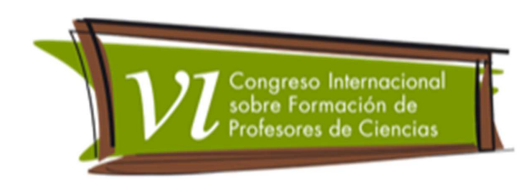

\title{
Las carnes curadas: una cuestión sociocientífica para favorecer el pensamiento crítico en docentes en formación inicial
}

Quiroga Karen', Verano Sandra²

Categoría 2. Trabajo de investigación (en proceso)

\section{Resumen}

En esta ponencia se presentan los resultados esperados y las posibles conclusiones de un trabajo de investigación sobre el diseño e implementación de una secuencia didáctica en torno a una cuestión socio-científica relacionada sobre el uso de nitritos en carnes curadas, con el propósito de potenciar el pensamiento crítico en docentes en formación inicial que cursan la asignatura del Énfasis didáctico II de la Licenciatura en Química de la Universidad Pedagógica Nacional, a través de la discusión de los aspectos controvertidos de la cuestión socio-científica analizada, permitiendo tanto la toma de decisiones a nivel social, cultural y personal por parte del estudiante respecto al lugar donde se consume este tipo de carnes, teniendo en cuenta las consecuencias que éstos conllevan en la salud humana al ser ingeridos constantemente, como la acción argumentativa de éstos.

\section{Palabras clave}

Cuestiones socio-científicas, pensamiento crítico, secuencia de enseñanza, nitritos en carnes.

\section{Objetivos}

General

Favorecer el pensamiento crítico en docentes en formación inicial a partir de una cuestión sociocientífica en torno al uso de nitritos en carnes curadas.

Específicos

Diseñar una secuencia didáctica basada en una cuestión socio-científica sobre el uso de nitritos en carnes curadas que favorezca el pensamiento crítico de los estudiantes que cursan la asignatura del Énfasis Didáctico II de la Licenciatura en Química de la Universidad Pedagógica Nacional.

\footnotetext{
1 Universidad Pedagógica Nacional. bibisupnacional@gmail.com

2 Universidad Pedagógica Nacional. sandrapverano@gmail.com
} 
Revista Tecné, Episteme y Didaxis: TED. Año 2014, Número Extraordinario. ISSN Impreso: 0121-3814, ISSN web: 2323-0126

Memorias, Sexto Congreso Internacional sobre Formación de Profesores de Ciencias. 08 al 10 de octubre de 2014, Bogotá

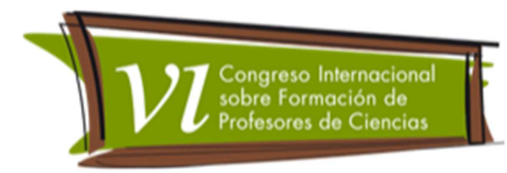

Evaluar las actividades de la secuencia didáctica a través del análisis argumentativo de los estudiantes participantes del estudio.

Favorecer el aprendizaje de los conceptos químicos desde el abordaje de una cuestión socio-científica relacionada con el uso de nitritos en carnes.

\section{Marco teórico}

Cuestiones socio-científicas:

La Enseñanza de las Ciencias centrada en el trabajo en cuestiones socio-científicas (CSC) en el aula, según Martínez y Parga (2013), favorece una educación abierta y crítica que potencializa la participación de los estudiantes contribuyendo con su formación ciudadana con el fin de comprender la ciencia como una actividad humana que presenta múltiples controversias e incertidumbres en su constitución y por tanto, requiere un análisis crítico de sus alcances e impactos.

De acuerdo con Zeidler y Nichols (2009) las CSC implican el uso deliberado de temas científicos que requieren los estudiantes para participar en el diálogo, la discusión y el debate. Por lo general requieren de un grado de razonamiento moral o la evaluación de los problemas éticos en el proceso de llegar a decisiones sobre la posible resolución de estas cuestiones; siendo así, es como el impacto social de las técnicas desarrolladas por la ciencia, requiere que los individuos se enfrenten a problemas multidisciplinares donde entran en juego intereses económicos, políticos, sociales y ambientales. De la misma forma, Martínez; Parga y Gómez (2012) establecen que en la contextualización social de las ciencias y en el análisis de las implicaciones éticas y morales surgen las cuestiones socio-científicas que abarcan discusiones, controversias o temas de interés público relacionados con investigaciones científicas y tecnológicas de gran impacto en la sociedad.

Para Martínez y Parga (2013) al trabajar dichas controversias socio-cientificas en clases de ciencias, tanto estudiantes como profesores desarrollan habilidades de argumentación, toma de decisiones, trabajo cooperativo y la generación de posturas a favor o en contra, de una determinada cuestión, de la misma forma que la necesidad de comprender los componentes sociales, políticos, económicos y ambientales alrededor de las cuales se puede tejer una controversia.

Pensamiento crítico:

El pensamiento crítico, según Beltrán y Torres (2009), es un proceso cognitivo que permite la construcción de un nuevo conocimiento y la utilización estratégica del

Temática 1. Enfoque CTS: Alfabetización científica y Cuestiones socio científicas 
Revista Tecné, Episteme y Didaxis: TED. Año 2014, Número Extraordinario. ISSN Impreso: 0121-3814, ISSN web: 2323-0126

Memorias, Sexto Congreso Internacional sobre Formación de Profesores de Ciencias. 08 al 10 de octubre de 2014, Bogotá

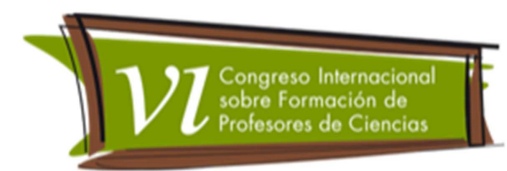

mismo en la solución de problemas presentes en la vida cotidiana; además de proporcionar a los estudiantes herramientas necesarias para saber el tipo de conocimiento que deben utilizar en determinada situación analizando la estructura y consistencia de los razonamientos, opiniones o afirmaciones que la gente acepta como verdaderas en el contexto de la vida cotidiana.

De acuerdo con Lazo y Herrera (2011) pensar críticamente define un pensamiento reflexivo y auto evaluativo (metacognición), el cual contribuye a que los estudiantes conozcan su sistema cognitivo (conocimientos, estrategias, motivaciones y sentimientos); para lo que resulta necesario contar con tres elementos básicos dados por el deseo de saber, la curiosidad, y el afán de verdad, estos son: el contexto, relacionado directamente con la situación, las estrategias, como procedimientos a operar en dicha situación y las motivaciones, refiriéndose a la relación entre el sujeto con el conocimiento.

Con el fin de lograr pensamiento crítico es preciso tener en cuenta que uno de los fines de la educación en ciencias es propiciar el desarrollo de habilidades cognitivas (operaciones mentales por las cuales el alumno dirige, controla y evalúa su propio proceso de pensamiento) que le permitan al estudiante transformar su contexto en busca de mejorar la calidad de vida (Solbes y Torres, 2013).

En esta investigación se analizarán las habilidades de razonamiento verbal y análisis de argumentos:

- Habilidades de razonamiento verbal y análisis de argumento: las cuales permiten identificar y valorar la calidad de las ideas, razones de un argumento y la conclusión del mismo. Además, permiten reconocer analogías dentro del lenguaje cotidiano.

Planteamiento y delimitación del problema:

Uno de los principales problemas actuales de la educación científica, según diversas investigaciones (Aikenhead, 2005; Jiménez-Aleixandre, 2010; Solbes y Torres, 2012; Solomon, 1996 citado en Solbes y Torres, 2013) está relacionado con la falta de pensamiento crítico en los estudiantes, lo cual implica que no estén preparados para solucionar diversos problemas en contexto, para tomar decisiones fundamentadas y generar respuestas argumentadas críticamente. De acuerdo con estos autores, su solución requiere que los docentes diseñen estrategias desde su campo de enseñanza 
Revista Tecné, Episteme y Didaxis: TED. Año 2014, Número Extraordinario. ISSN Impreso: 0121-3814, ISSN web: 2323-0126

Memorias, Sexto Congreso Internacional sobre Formación de Profesores de Ciencias. 08 al 10 de octubre de 2014, Bogotá

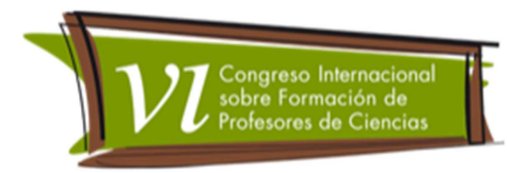

que permitan no solo el aprendizaje de la disciplina sino que además generen espacios de discusión y reflexión, sobre todo porque cuando los miembros de una sociedad carecen de pensamiento crítico están expuestos a múltiples abusos por parte de diversos agentes y sus intereses.

En este sentido, surge la necesidad de que los docentes en formación inicial participantes del estudio potencien su pensamiento crítico a partir del desarrollo de habilidades como el razonamiento verbal y el análisis argumentativo a través de la implementación de una secuencia didáctica centrada en el análisis de una CSC en torno a el uso de nitritos en carnes curadas, permitiendo la toma de decisiones a nivel social, cultural y personal por parte del estudiantado respecto al lugar donde se consume este tipo de carnes, teniendo en cuenta los efectos que puede ocasionar en la salud humana al ser consumidos frecuentemente.

A partir de lo anterior, ¿Cómo contribuye la elaboración de una secuencia didáctica basada en una CSC sobre el uso de nitritos en carnes curadas, para favorecer el pensamiento crítico en docentes en formación inicial?

Metodología:

Enfoque metodológico: Este trabajo de investigación se fundamenta en un estudio metodológico cualitativo en términos de discutir las implicaciones socio-científicas del uso de nitritos en carnes curadas y el desarrollo del pensamiento crítico en los docentes en formación inicial.

Población: El trabajo de investigación se va a desarrollar en la Universidad Pedagógica Nacional ubicada en la ciudad de Bogotá, D.C con profesores en formación inicial que cursan la asignatura del Énfasis Didáctico II de la Licenciatura en Química.

Las fases en las cuales se desarrollará la investigación son: 
Revista Tecné, Episteme y Didaxis: TED. Año 2014, Número Extraordinario. ISSN Impreso: 0121-3814, ISSN web: 2323-0126

Memorias, Sexto Congreso Internacional sobre Formación de Profesores de Ciencias. 08 al 10 de octubre de 2014, Bogotá

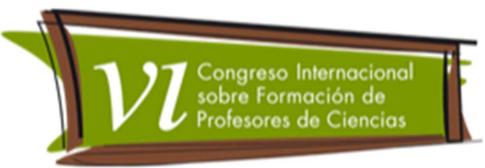

\section{Esquema 1. Metodología del proyecto de investigación}
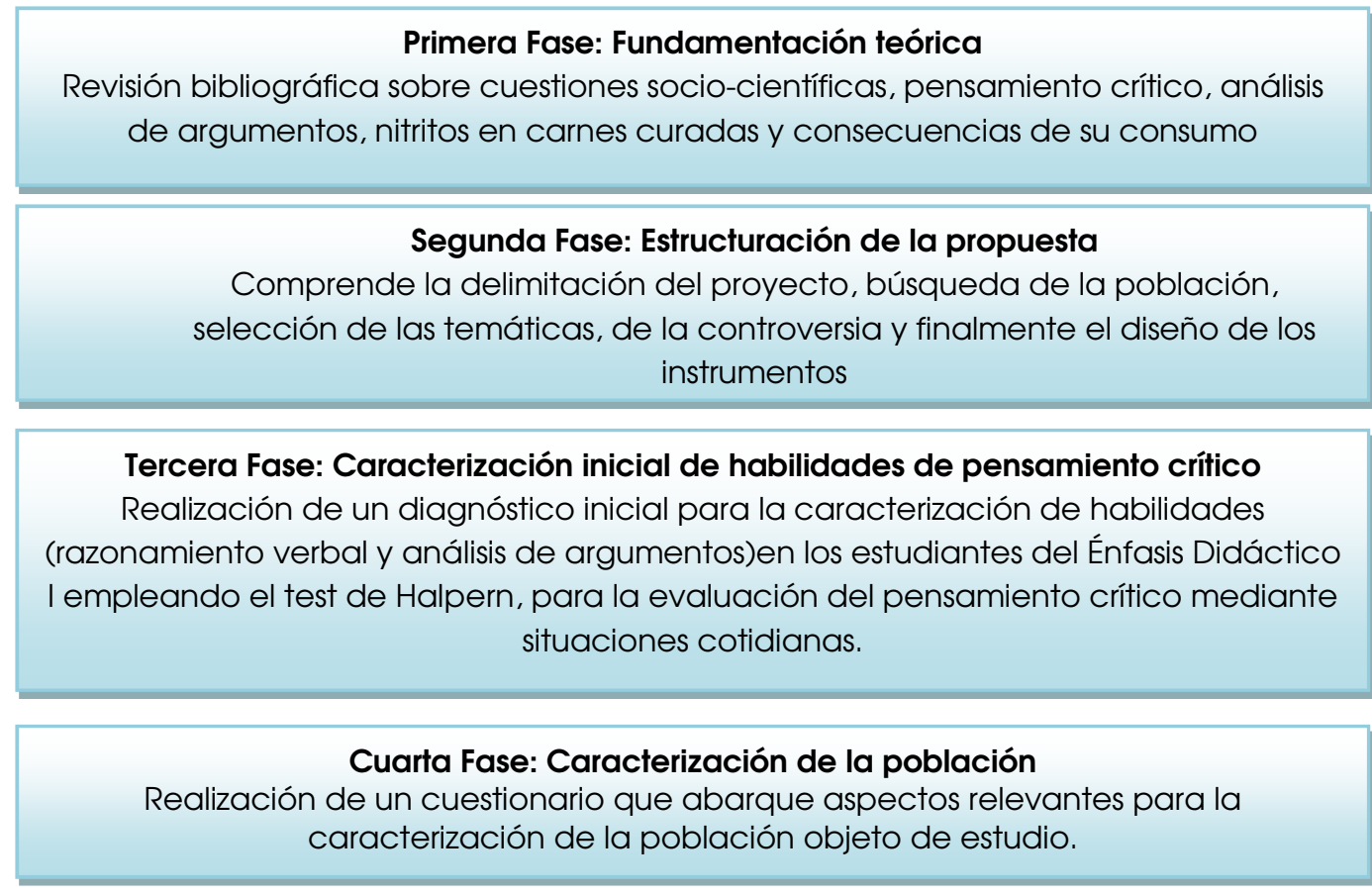

Quinta Fase: Diseño e implementación de una secuencia didáctica

Elaboración e implementación de una secuencia didáctica orientada a partir del aborde de una cuestión socio-científica relacionada sobre el uso de nitritos en carnes curadas, en donde se encuentran diversas actividades, tales como: debates, reflexiones y análisis de lecturas, artículos noticiosos, videos, y comerciales referidos al tópico propuesto.

\section{Sexta Fase: Evaluación de la secuencia didáctica}

Evaluación de la secuencia didáctica a partir del análisis argumentativo de los alumnos participantes, teniendo en cuenta las grabaciones en audio, la observación directa, los videos de las discusiones generadas por éstos y lo escrito en los instrumentos de la secuencia didáctica.

\section{Séptima Fase: Análisis de resultados}

Realización del análisis respecto a cómo los docentes en formación inicial desarrollan el pensamiento crítico en torno a la cuestión socio-científica abordada, según los resultados obtenidos. 
Revista Tecné, Episteme y Didaxis: TED. Año 2014, Número Extraordinario. ISSN Impreso: 0121-3814, ISSN web: 2323-0126

Memorias, Sexto Congreso Internacional sobre Formación de Profesores de Ciencias. 08 al 10 de octubre de 2014, Bogotá

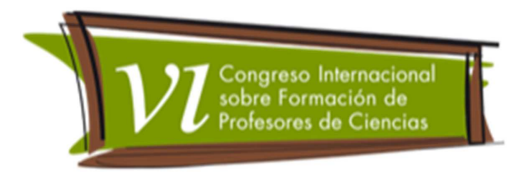

\section{Resultados esperados}

Los resultados esperados al finalizar la aplicación de la secuencia didáctica es el desarrollo del pensamiento crítico en profesores de Química en formación inicial al desarrollar ciertas habilidades (razonamiento verbal y análisis de argumentos) a partir del análisis de una cuestión socio-científica sobre el uso de nitritos en carnes curadas. Asimismo, permitiendo la toma de decisiones por parte del estudiante, lo cual permite establecer criterios al momento de consumir estos alimentos, teniendo en cuenta las implicaciones que éstos conllevan en diferentes aspectos como lo son: político, económico, cultural, ambiental, social y los riesgos en la salud humana.

\section{Posibles conclusiones}

La propuesta de diseñar una secuencia didáctica abordada desde el enfoque de CSC, favoreció el pensamiento crítico, ya que permite al estudiante desarrollar procesos de pensamiento y de discurso, a través de respuestas elaboradas, en las cuales se denota un alto nivel de argumentación, donde se evidencia la toma de decisiones a partir de la posición política, social, cultural, ambiental y económica que el docente en formación inicial toma frente al tema de discusión referente al uso desmedido de conservantes en carnes curadas, a las condiciones de calidad y salubridad con que estos productos se comercializan y a los efectos que conllevan en la salud humana.

El diseño de una secuencia didáctica permite al docente encontrar una forma de guiar y formar al estudiante como sujeto que resuelve y plantea soluciones a cualquier tipo de cuestión que genere polémica y afecte su entorno social, contribuyendo así a la formación de ciudadanos que aporten y participen en la sociedad, valiéndose de su conocimiento científico, tecnológico, político, económico, cultural y ambiental, todo esto orientado con la polémica sobre el uso de nitritos en el proceso de curado de las carnes.

\section{Referencias bibliográficas}

Antón, A., \& Lizaso, J. (2010). Nitritos, Nitratos y Nitrosaminas. Mundo Lácteo y Cárnico, 26-30.

Beltrán, M., \& Torres, N. (2009, Diciembre). Caracterización de habilidades de pensamiento crítico en estudiantes de educación media a través del test HCTAES. Revista del Instituto de estudios en educación Universidad del Norte (11). 
Revista Tecné, Episteme y Didaxis: TED. Año 2014, Número Extraordinario. ISSN Impreso: 0121-3814, ISSN web: 2323-0126

Memorias, Sexto Congreso Internacional sobre Formación de Profesores de Ciencias. 08 al 10 de octubre de 2014, Bogotá

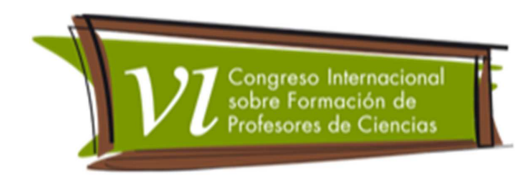

Lazo, L., \& Herrera, H. (2011). Aplicación de un modelo de intervención pedagógica que desarrolla estrategias de pensamiento crítico para estudiantes de carreras del área de ciencias. Revista electrónica diálogos educat ivos (21).

Martínez, L. F., \& Parga, D. L. (2013). La emergencia de las cuestiones socio-científicas en el enfoque CTSA. Góndola, 8 (1), 23-25.

Martínez, L., Parga, D. , \& Gómez, D. (2012). Cuestiones socio científicas en la Formación de Profesores de Ciencias. Revista EDUCYT.

Solbes, J., \& Torres, N. (2012). Análisis de competencias del pensamiento crítico desde el aborde de las cuestiones socio-científicas: un estudio en el ámbito universitario. Didáctica de las ciencias experimentales y sociales. (26), 247 - 269.

Solbes, J., \& Torres, N. (2013). ¿Cuáles son las concepciones de los docentes de ciencias en formación y en ejercicio sobre el pensamiento crítico?. TED Tecné, Episteme y Didaxis, 61-85.

Zeidler, D., \& Nichols, B. (2009). Cuestiones socio cientificas: teoría y práctica. Journal of elementary science education, 21 (2), 49-58. 